\title{
Brain activity assessment by functional MRI before and after radiofrequency of gasserian ganglia in patients with trigeminal neuralgia
}

\author{
Mohamed Abdallah, Sherif Khalil, Ayman Hamed, Radwa K. Soliman, Abdelraheem Mohamed \\ Author affiliations: \\ 1- M.B. Bch. Master Degree in Anesthesiology \& Intensive Care, Faculty of Medicine - Assiut University, Assiut, Arab \\ Republic of Egypt. \\ 2- Professor of Anesthesiology \& Intensive Care, Faculty of Medicine, Assiut University, Assiut, Arab Republic of Egypt. \\ 3- Lecturer, Department of Diagnostic Radiology, Faculty of Medicine, Assiut University, Assiut, Arab Republic of Egypt. \\ 4- Assistant Professor of Anesthesiology \& Intensive Care, Faculty of Medicine, Assiut University, Assiut, Arab Republic of \\ Egypt.
}

Correspondence: Mohamed Abdallah, M.B. Bch. Master Degree in Anesthesiology \& Intensive Care, Faculty of Medicine, Assiut University, Assiut-71515, Arab Republic of Egypt.

\section{Abstract}

Background and Objectives: Trigeminal neuralgia (TN) is one of the common causes of facial pain. However, its treatment is a challenge. Radiofrequency (RF) is an effective and safe option that is available. In our study, we used functional Magnetic resonance imaging ( $\mathrm{FMRI}$ ) to assess levels of brain activity in patients with TN, before and after receiving radiofrequency.

Methodology: This study is a randomized prospective clinical study. It included 30 patients with TN who were scheduled for thermal (i.e. conventional) radiofrequency (CRF) and pulsed radiofrequency (PRF). 15 patients were randomly assigned to each group. All patients were contacted before the intervention and then 1 week, 1 month, 3 months, and 6 months after the intervention. They were assessed using the Visual Analogue Scale (VAS) score, and their complaints of facial numbness, muscles of mastication dysfunction and carbamazepine dose. $\mathrm{fMRI}$ was done before and one month after the intervention.

Results: The study group comprised of 13 men and 17 women; a total of 30 patients. The mean age of patients was 50.60 \pm 12.06 years in the thermal radiofrequency group and $47.93 \pm 9.90$ years in the pulsed radiofrequency group. The median VAS score before the procedure was 8 in both groups, (7-9) in CRF and (7-8) in PRF. Our study demonstrated a statistically significant difference in VAS score at different stages of follow-up after thermal radiofrequency and pulsed radiofrequency when compared with the pretreatment stage. PRF patients continued on medications. Mild complications as facial numbness and masticatory muscle weakness were reported in the CRF group. In some brain regions, fMRI revealed reduced BOLD signal activation after radiofrequency ablation compared to that before the radiofrequency therapy but it was not significant.

Conclusion: In our study, post-intervention $\mathrm{fMRI}$ revealed a reduction in signal activations of some brain regions but we could not correlate these changes with the clinical improvement. Radiofrequency is an effective treatment for trigeminal neuralgia. CRF is preferable as it had less complications.

Key words: fMRI; Trigeminal neuralgia; Pulsed Radiofrequency; Thermal radiofrequency

Citation: Abdallah M, Khalil S, Hamed A, Soliman RK, Mohamed A. Brain activity assessment by functional MRI before and after radiofrequency of gasserian ganglia in patients with trigeminal neuralgia. Anaesth. pain intensive care 2020;24(6):612-621; DOI: https://doi.org/10.35975/apic.v24i6.1398

Received: 30 July 2020, Reviewed: 6 October 2020, Revised: 29 October 2020, Accepted: 30 October 2020 
Abbreviations: fMRI - functional Magnetic Resonance Imaging, RF - Radiofrequency, CRF - Conventional Radiofrequency, PRF - Pulsed Radiofrequency, TN - Trigeminal Neuralgia, BMI - Body mass index, VAS - Visual Analogue Scale, BOLD - Blood Oxygen Level-Dependent, ReHo - Regional Homogeneity, ALFF - Amplitude of Low Frequency fluctuations.

\section{Introduction}

Trigeminal neuralgia (TN) is one of the most common causes of facial pain. Yet, there are no ideal therapeutic options available and its treatment is considered to be challenging. ${ }^{1}$ It was estimated to have a prevalence of 12.6-28.9 per 100,000 in the general population per year. ${ }^{2}$

$\mathrm{TN}$ is more common in females than males at a ratio of 2:1, and is more common in old age. ${ }^{3,4}$ Almost $90 \%$ of TN cases are idiopathic. Secondary causes include multiple sclerosis, tumors, herpes zoster, and arteriovenous malformation. The right side of the face is more affected than the left side (3:1), possibly due to narrower foramen rotundum and foramen ovale on the right side. ${ }^{5,6}$

The International Headache Society defines the diagnostic criteria for TN. ${ }^{7,8}$ Diagnosis is confirmed in cases where the patient had at least 3 unilateral facial pain attacks with the following characteristics:

- $\quad$ Meets at least 1 of the following 4 criteria: (1) paroxysmal and lasting between a fraction of a sec and 2 min; (2) severe; (3) shock-like, shooting, stabbing, or sharp; (4) precipitated by non-painful stimuli.

- The neuropathic pain exists in at least one division of the nerve with no radiation outside its distribution.

- Neurological disorders and all other known causes are not identified.

Medical treatment for $\mathrm{TN}$ is considered the first-line treatment as it is effective in treating about $60 \%$ of the $\mathrm{TN}$ patients. Different medications have been considered for the treatment of TN such as anticonvulsants, carbamazepine and oxcarbazepine. Other medications such as baclofen, lamotrigine gabapentin, pregabalin, topiramate, and valproate can be also used. ${ }^{9}$
Surgical interventions are used for patients whose symptoms don't show improvement despite a trial of at least 3 drugs or in whom medications caused unacceptable adverse effects. Relapse of symptoms might be another strong factor in opting for surgical treatment. ${ }^{10}$ However, the treatment of refractory cases of $\mathrm{TN}$ is still a big problem; with an annual incidence of recurrent $\mathrm{TN}$ after surgical options ranging from 1$5 \% .^{11}$

By far, one of the most common procedures to treat pain is the use of radiofrequency (RF) lesioning. The main advantages of RF seem to be its effectiveness and high pain relief rate without the dangerous complications of surgical procedures and a lack of secondary effects of oral medication. ${ }^{12}$ Pulsed radiofrequency (PRF) uses a lower temperature application of energy produced by the radiofrequency generator at the tip of the needle and diffuses the energy to the nerve in a pulsatile manner. The thermal radiofrequency (TRF) uses electrical current to heat the nerve and aims to stop a nerve from transmitting pain signals. ${ }^{13}$

Functional magnetic resonance imaging (fMRI) is a non-invasive, indirect method of measuring neural activities dependent on changes in the level of blood oxygen (BOLD effect). ${ }^{14}$ Changes in the blood flow via capillary beds are thought to represent changes in neural activities or possible changes in the dendritic region. This method measures variations in brain regions based on changes in proportional hemoglobin and deoxyhemoglobin levels. With the increased volume, the venous side of capillary blood supply experiences a relative decrease in deoxyhemoglobin. ${ }^{15}$

In our study, we used fMRI to assess brain activity before RF ablation of gasserian ganglia and post treatment.

\section{Methodology}

This randomized prospective study included 30 patients with TN who presented to Assuit University 
Hospital between January 2018 and September 2019 and were scheduled for RF therapy of Gasserian ganglia. fMRI assessment before and after radiofrequency was done. Two approaches of RF ablation were used in our study; thermal and pulsed. Patients were randomly allocated to either approach. Written informed consent was obtained from all patients after explaining the procedures, the potential side effects and possible outcomes. Approval was obtained from the local ethics committee of Faculty of Medicine, Assuit University.

\subsection{Sampling}

All TN patients who met the following inclusion criteria were randomly assigned to one of the two treatment groups, 15 patients in each group; patients ages $40-65$ yrs, with primary $\mathrm{TN}$, affecting maxillary and/or mandibular branch only, and in which medical treatment had failed. Patients with secondary and/or recurrent $\mathrm{TN}$, or those with ophthalmic branch affection were excluded. Patients with known contraindication for intervention, e.g., sepsis, coagulopathy, infection at entry point, local anesthetic allergy and pregnant females were also excluded.

All participants were subjected to the following:

\subsubsection{Pre-interventional evaluation}

It included record of personal data; pain: onset, course, duration, and severity, visual analog scale assessment (VAS), previous interventions and concurrent medical illnesses.

\subsubsection{Clinical examination}

General, local and neurological examination was done and the findings recorded.

\subsubsection{Investigations}

Basic blood tests and coagulation studies were done to rule out any irregularities.

\section{2 fMRI}

The experimental design was similar to that designed by Moisset et al. A cotton swab, connected to a plastic stick, was used as a stimulus. Light tactile stimulation was applied, with a frequency of one per second, on the trigger zone and on the contralateral homologous side. Stimulation was applied in a block design format; four epochs of rest alternating with three epochs of tactile stimulation. Each epoch lasted for $27 \mathrm{sec}$.

\subsubsection{Procedure}

Patients were taken to the operating room where they laid comfortably in the supine position with slightly extended head. They were connected to standard monitoring including electrocardiogram (ECG), noninvasive blood pressure, and pulse oximeter. Through a postero-anterior manner the $\mathrm{C}$-arm was introduced and rotated caudo-cranially to provide a submental view. With this view, the foramen ovale was visualized. A 5-10 degree tilt to the affected side was made if necessary to enhance the visualization of the foramen oval, the point of entry of the needle being 2$3 \mathrm{~cm}$ from the angle of the mouth. 'Bringing of the foramen ovale to the point of entry' method was applied by manipulating the $\mathrm{C}$-arm in a caudo-cranial orientation to create an excellent tunnel view.

Using aseptic technique skin above the point of entry of the needle was anesthetized with $1 \%$ lidocaine. The needle was directed towards the ipsilateral pupil. A finger was placed in the patient's mouth to reduce the risk of having a needle penetrate the oral cavity. Before insertion of the needle, we used up to 0.75 $\mathrm{mg} / \mathrm{kg}$ of propofol to sedate the patient. When the needle penetrated the foramen ovale in the Meckel's cavity, the C-arm was rotated laterally to assess the penetration depth. The final location of the needle tip was just beyond the angle created by the petrosal ridge of the temporal bone and clivus. The sedation of propofol was stopped, the patient was allowed to awaken and sensory stimulation was performed at 50 $\mathrm{Hz}$. The electrode's definitive location was confirmed by inducing sensory stimulation paresthesia in the affected painful area between $0.1-0.3 \mathrm{~V}$, then TRF was applied in 15 patients for 2 cycles of $90-\mathrm{sec}$ at $70^{\circ} \mathrm{C}$ or PRF was applied in 15 patients for $10 \mathrm{~min}$ at $42^{\circ} \mathrm{C}$. The patients were discharged from hospital after two hours of follow-up.

\subsection{2 fMRI Protocol}

All subjects were examined in supine position, both before and one month after the RF ablation using 1.5T Phillips scanner with multi-channel head coil. Functional images were acquired using T2-weighted gradient echo planner (EPI) sequence (TR/TE= $3000 / 50 \mathrm{~ms}$, Flip angle $=90$, FOV 210 $\times 210$ slice thickness $=4 \mathrm{~mm}$ ), whereas anatomical images were acquired using 3D TFE T1-weighted image sequence 
$(\mathrm{TR} / \mathrm{TE}=140 / 7 \mathrm{~ms}$, FOV 224x 244 slice thickness= $2 \mathrm{~mm})$.

\subsubsection{Follow up}

All patients were contacted before the intervention, 1 week, 1 month, 3 months and 6 months after the interventions to rate their pain using the VAS score. They were also asked about complaints regarding facial numbness, muscle of mastication affection, duration of attack and carbamazepine dose. fMRI was done before the intervention and one month after the intervention.

\subsection{Statistical analysis}

\subsubsection{Radiofrequency analysis}

SPSS version 23.0 was used for data management and analysis. Mean \pm standard deviation or median and range when appropriate, were used to describe quantitative data. Numbers with percentages described qualitative data. The Chi-square test and Fisher Exact test was used to compare independent categorical variables. Where continuous data were normally distributed, the Student's T-test was used for comparisons between two groups; where data were non- normally distributed, the Mann-Whitney test and Friedman test were used. P-value was twotailed and considered significant at 0.05 .

\subsubsection{Image analysis}

Functional data analysis was performed using SPM12.

\subsubsection{Pre-processing:}

For each subject, realignment of the functional images was first performed for motion correction. It was followed by co-registration of the mean EPI volume with the T1-weighted images. Segmentation and normalization to the Montreal neurological institute (MNI) was then achieved. Spatial smoothing to the normalized volumes was then applied to increase the signal to noise ratio and to increase the validity of statistical inference for statistical analysis. Six subjects had to be excluded due to the low quality of the data set. Therefore, a total of twenty four subjects were included in the final fMRI analysis.

\subsubsection{Processing:}

General linear model approach was constructed and fMRI time series data were fit to the design matrix. The parameter estimates for the stimulus epochs were contrasted to rest epochs for each patient (for both the trigger zone and the contralateral homologous side). The first level analysis, using one sample t-test, was performed for each subject at both sides (affected and non-affected) both before and after the RF ablation. Second level analysis was then performed, using two sample t- test, to compare the affected versus the nonaffected side. Eventually, paired t- test was used to compare the statistical maps before versus after RF ablation. Regions with uncorrected $\mathrm{p}<0.001$ were considered as significant.

\section{Results}

\subsection{Demographic data}

This study group comprised of 13 men and 17 women for a total of 30 patients. Age is a major risk factor for idiopathic TN; the mean age of presentation was 50.60 \pm 12.06 years in the CRF group and $47.93 \pm 9.90$ years in the PRF group. Although the disease can occur at any age, the age range for this study was 40-60 years. Obesity is a well-established promoter of chronic pain, pain sensitization, and neuropathic pain. The estimated mean BMI was $25.47 \mathrm{~kg} / \mathrm{m}^{2}$ and 25.40 $\mathrm{kg} / \mathrm{m}^{2}$ in the CRF and PRF groups respectively. The duration of TN was 2-7 years with a mean of 3.87 years in the CRF group. However, it ranged from 2 to 6 years with a mean of 3.47 years in the PRF group. There was no statistically significant difference between the groups regarding age, gender, BMI, duration of disease and the site of the pain.

\subsection{Pain intensity}

The median of the VAS score before the intervention was 8; 7-9 in the CRF group, and 7-8 in the PRF group. Results of this study show that there is a statistically significant difference in VAS at different stages of follow-up after CRF and PRF when compared with pre-interventional stage [Table 1].

\subsection{Additional pharmacological treatment}

We found no significant difference between the two groups regarding the need for medical treatment after the intervention in the first week and first month. However, there was a statistically significant difference in the CRF group than in the PRF group (p $<0.001)$ in the $3^{\text {rd }}$ and $6^{\text {th }}$ month after the 
intervention. PRF patients was continued on

medications [Table 2].

Table 1: VAS score in two groups at different times of treatment [values expressed as Median (range)

\begin{tabular}{lcc|c|c|c|c|c}
\multicolumn{1}{c}{ Study group } & $\begin{array}{c}\text { VAS } \\
\text { pretreatment }\end{array}$ & $\begin{array}{c}\text { VAS after } \\
\text { one week }\end{array}$ & $\begin{array}{c}\text { VAS after } \\
\text { one month }\end{array}$ & $\begin{array}{c}\text { VAS after 3 } \\
\text { months }\end{array}$ & $\begin{array}{c}\text { VAS after 6 } \\
\text { months }\end{array}$ & $\begin{array}{c}\text { P value for } \\
\text { time effect }\end{array}$ \\
\hline $\begin{array}{l}\text { Conventional } \\
\text { radiofrequency (CRF) }\end{array}$ & $8(7-9)$ & $4(3-5)$ & $3(2-4)$ & $2(2-3)$ & $2(1-3)$ & $<0.001^{*}$ \\
\hline $\begin{array}{l}\text { Pulsed } \\
\text { radiofrequency (PRF) }\end{array}$ & $8(7-8)$ & $5(4-6)$ & $4(3-5)$ & $3(2-4)$ & $4(3-5)$ & $<0.001^{*}$ \\
\hline
\end{tabular}

Table 2: Need of medical treatment in the two study groups

\begin{tabular}{|c|c|c|c|c|}
\hline \multirow{3}{*}{\multicolumn{2}{|c|}{ Need medication }} & \multicolumn{2}{|c|}{ Study group } & \multirow{3}{*}{$P$ value } \\
\hline & & \multirow{2}{*}{$\begin{array}{c}\text { Conventional } \\
\text { radiofrequency (CRF) } \\
\text { Count }(\%)\end{array}$} & \multirow{2}{*}{$\begin{array}{c}\text { Pulsed radiofrequency } \\
\text { (PRF) } \\
\text { Count }(\%) \\
\end{array}$} & \\
\hline & & & & \\
\hline \multirow{2}{*}{ Pre treatment } & yes & $15(100)$ & $15(100)$ & \multirow{2}{*}{1.0} \\
\hline & no & $0(0)$ & $0(0)$ & \\
\hline \multirow{2}{*}{ After 1 week } & yes & $15(100)$ & $15(100)$ & \multirow{2}{*}{1.0} \\
\hline & no & $0(0)$ & $0(0)$ & \\
\hline \multirow{2}{*}{ After 1 month } & yes & $15(100)$ & $15(100)$ & \multirow{2}{*}{1.0} \\
\hline & no & $0(0)$ & $0(0)$ & \\
\hline \multirow{2}{*}{ After 3 months } & yes & $3(20)$ & $15(100)$ & \multirow{2}{*}{$<0.001^{*}$} \\
\hline & no & $12(80)$ & $0(0)$ & \\
\hline \multirow{2}{*}{ After 6 months } & yes & $1(6.7)$ & $15(100)$ & \multirow{2}{*}{$<0.001^{\star}$} \\
\hline & no & $14(93.3)$ & $0(0)$ & \\
\hline
\end{tabular}

Table 3: Complications of radiofrequency in the two study group

\begin{tabular}{|c|c|c|c|c|}
\hline \multirow{3}{*}{ Time } & \multirow{3}{*}{ Complication } & \multicolumn{2}{|c|}{ Study group } & \multirow{3}{*}{ p-value } \\
\hline & & $\begin{array}{c}\text { Conventional } \\
\text { radiofrequency (CRF) }\end{array}$ & $\begin{array}{l}\text { Pulsed radiofrequency } \\
\text { (PRF) }\end{array}$ & \\
\hline & & Count $(\%)$ & Count (\%) & \\
\hline \multirow{3}{*}{1 week } & Numbness & $11(73.3)$ & $0(0)$ & $<0.001^{*}$ \\
\hline & no complication & $0(0)$ & $15(100)$ & \\
\hline & numbness \& muscle weakness & $4(26.7)$ & $0(0)$ & \\
\hline \multirow{3}{*}{1 month } & Numbness & $11(73.3)$ & $0(0)$ & $<0.001^{*}$ \\
\hline & no complication & $0(0)$ & $15(100)$ & \\
\hline & numbness \& muscle weakness & $4(26.7)$ & $0(0)$ & \\
\hline \multirow{3}{*}{3 months } & Numbness & $13(86.7)$ & $0(0)$ & $<0.001^{*}$ \\
\hline & no complication & $0(0)$ & $15(100)$ & \\
\hline & numbness \& muscle weakness & $2(13.3)$ & $0(0)$ & \\
\hline \multirow{2}{*}{6 months } & Numbness & $10(66.7)$ & $0(0)$ & \\
\hline & no complication & $5(33.3)$ & $15(100)$ & $<0.001^{*}$ \\
\hline
\end{tabular}




\subsection{Complications}

Regarding complications, some patients in the CRF group had facial numbness and mastication muscle weakness. These complications were mild in nature and improved with time. There was no reported complications in the PRF group [Table 3].

Figure 1: BOLD signal activation pattern of the affected side versus the non-affected side before RF ablation. Regions with uncorrected $P<0.001$ were considered significant. Height threshold: $T=2$. The name of the regions are shown in Table 4.
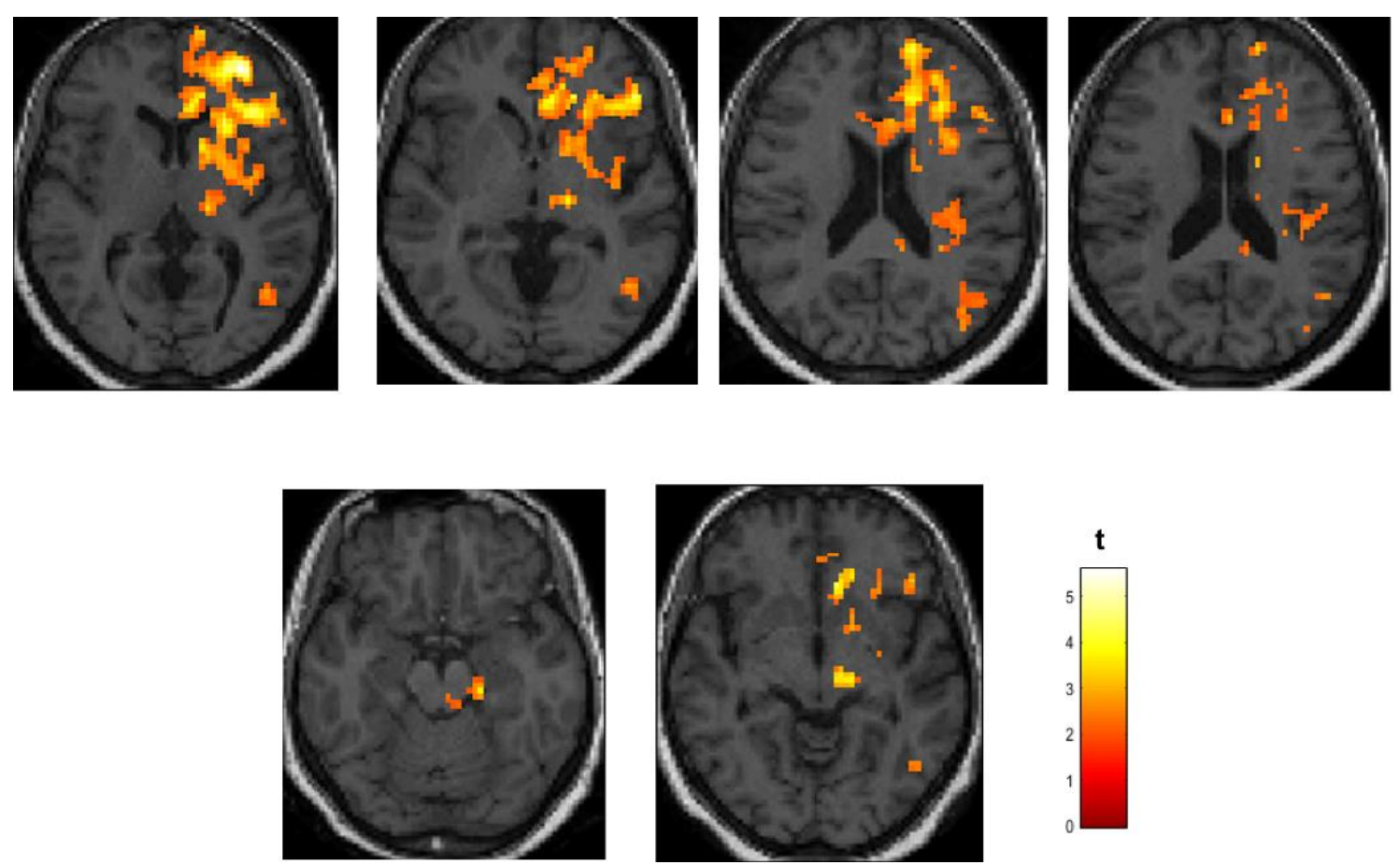

Table 4: BOLD signal activation in the brain and average $Z$ - score of the affected side versus the non-affected side before RF ablation

\begin{tabular}{|c|c|c|c|c|c|}
\hline \multicolumn{6}{|c|}{ Affected side $>$ not affected side } \\
\hline Area & & z-score & $\mathbf{x}$ & $\mathbf{Y}$ & $\mathbf{Z}$ \\
\hline Parietal operculum (SII) & left & 2.10 & -39 & -29 & 18 \\
\hline Angular gyrus & left & 2.64 & -44 & -57 & 50 \\
\hline Superior frontal cortex & left & 3.12 & -21 & 39 & 42 \\
\hline Middle frontal cortex & left & 3.72 & -26 & 15 & 26 \\
\hline Frontal operculum & left & 3.30 & -36 & 28 & 2 \\
\hline Anterior insula & left & 2.72 & -23 & 21 & 2 \\
\hline Posterior insula & left & 2.08 & -43 & -10 & 3 \\
\hline Anterior cingulate & left & 2.64 & -7 & 32 & 25 \\
\hline Para-hippocampus & left & 2.70 & -18 & -26 & $\begin{array}{l}-18 \\
\end{array}$ \\
\hline Putamen & left & 2.63 & -19 & 6 & 2 \\
\hline Caudate & left & 3.45 & -13 & 10 & 6 \\
\hline Thalamus & left & 2.79 & -13 & -18 & 14 \\
\hline Ventral diencephalon & left & 2.79 & -16 & -21 & -6 \\
\hline
\end{tabular}

$p<0.001$, height threshold: $T=2$. Brain coordinate: $X, Y, Z ; X=$ medial to lateral, $Y=$ anterior to posterior, $Z$ = superior to inferior 

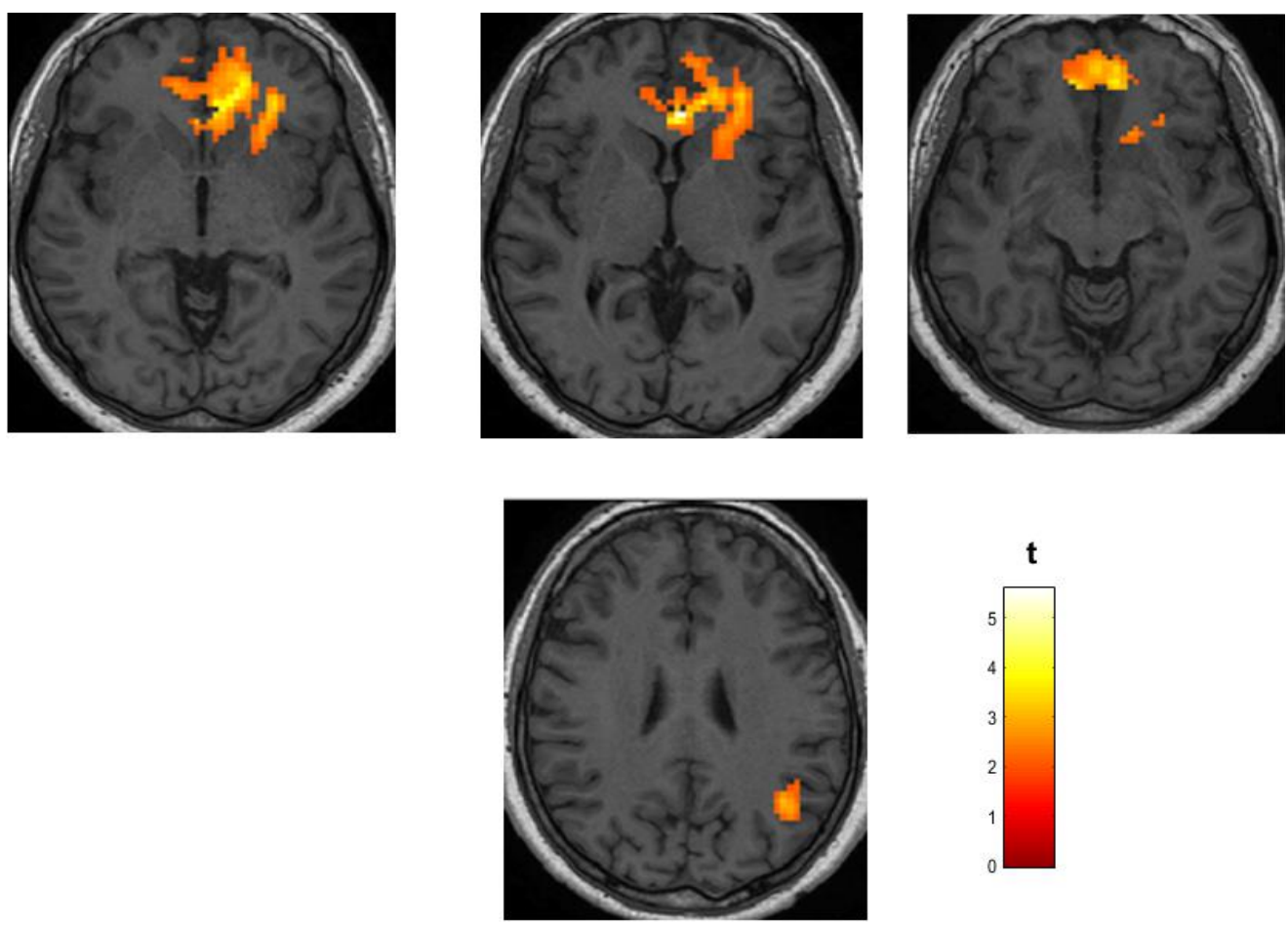

Figure 2: BOLD signal activation pattern of the affected side versus the non-affected side after the RF ablation. Regions with uncorrected $p<0.001$ were considered significant. Height threshold: $T=2$. The name of the regions are shown in Table 5.

Table 5: BOLD signal activation in the brain and average Z- score of the affected side versus the non-affected side after RF ablation:

\begin{tabular}{|c|c|c|c|c|c|}
\hline \multirow{2}{*}{ Area } & & \multicolumn{4}{|c|}{ Affected side > Unaffected side } \\
\hline & & z-score & $\mathbf{x}$ & $\mathbf{y}$ & $\mathbf{z}$ \\
\hline Angular cortex & Left & 2.61 & -49 & -55 & 22 \\
\hline Superior frontal cortex & Left & 2.52 & -9 & 49 & 2 \\
\hline \multirow{2}{*}{ Middle frontal cortex } & Left & 2.96 & -8 & 44 & -10 \\
\hline & Right & 2.61 & 3 & 53 & -10 \\
\hline Anterior insula & Left & 2.31 & -26 & 26 & -2 \\
\hline \multirow{2}{*}{ Anterior cingulate cortex } & Left & 3.98 & -5 & 31 & 2 \\
\hline & Right & 3.98 & 3 & 35 & 2 \\
\hline
\end{tabular}

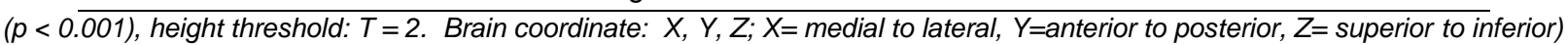

\section{5 fMRI results}

\subsubsection{Before Radiofrequency (RF) ablation}

Comparing the fMRI between the affected and unaffected sides revealed significant activation in the following regions: secondary somatosensory area, angular gyrus, frontal cortex (including the superior and middle frontal cortices and frontal operculum), para-hippocampus, anterior and posterior insula, anterior cingulate cortex as well as thalamic, putamen and caudate nuclei and the ventral diencephalon (Table 4; Figure1)

\subsubsection{After 1 month of RF}

There was significant brain activation evident at the primary somatosensory area and angular gyrus as well 
as in the superior and middle frontal cortices, in addition to the anterior insula and anterior cingulate cortex (Table 5, Figure 2).

Therefore, reduced BOLD signal activation was observed in some brain regions after radiofrequency ablation compared to that before the radiofrequency. This includes the secondary somatosensory area and space in the frontal operculum. In addition, activation was also reduced in the para-hippocampus, posterior insula, the caudate, putamen, thalamic nuclei and ventral diencephalon.

\subsubsection{Comparison of fMRI pre- and post RF ablation}

The paired t-test was used and revealed no area of significant activation.

\section{Discussion}

$\mathrm{TN}$ is one of the common causes of facial pain worldwide that significantly effects quality of life and is even linked to increased suicide rates. Several modalities of treatment are available for this neuropathic pain. First line of treatment is usually medical; especially anticonvulsants, of which carbamazepine is the drug of choice, Carbamazepine blocks sodium channels which decreases depolarization of the affected neurons. Other medications that can be used include baclofen, gabapentin, clonazepam, sodium

valproate, lamotrigine, and topiramate. Some of these are helpful in refractory cases too. Coming to surgical options, there is a variety that can be recommended to patients who are not responding to medical treatment or develop side effects that cannot be tolerated. There are microvascular decompression, Gamma Knife and radiofrequency.

In our study, we monitored the brain response to radiofrequency using fMRI before and after therapy. We also compared the efficacy of pulsed RF and conventional RF in the treatment of TN using the VAS score and assessing the need for additional medical treatment and complications at the $1^{\text {st }}$ week, $1^{\text {st }}$ month, $3^{\text {rd }}$ month and $6^{\text {th }}$ month after the intervention.

PRF uses a lower temperature application of energy produced by the radiofrequency generator at the tip of the needle and diffuses the energy to the nerve in a pulsed manner to decrease thermal destruction.
Whereas, TRF involves high-temperature effects of high-frequency current on the Gasserian ganglia. ${ }^{16}$

Functional MRI is based on the Bold effect (blood oxygen level-dependent changes) that measures the oxygenated hemoglobin and deoxyhemoglobin concentration in various brain regions at baseline and during activity. ${ }^{17}$

In the present study, there was a statistically significant difference in VAS scores at different time points of follow-up compared with the preintervention results.

A similar pattern of results was obtained by Elawamy et al. in 2017, who described that complete pain relief was found immediately after the procedure in all patients up to the $3^{\text {rd }}$ month of follow-up. After that, the pain began to return in the PRF group rather than in the CRF group. ${ }^{17}$ The VAS score for patients in the PRF was increased at the $6^{\text {th }}$ month post treatment. Thermocoagulation offers the highest rates of complete pain relief with percentages more than $90 \%$, as detailed in a number of previously done studies. ${ }^{18-}$ 22

In our study, regarding the for medical therapy in the first week and the first month, there was no statistically significant difference between the two groups. However, the need for medical therapy was decreased in the TRF group at the $3^{\text {rd }}$ and $6^{\text {th }}$ month. But patients who received PRF continued on medical treatment at these follow-up periods.

Coming to side effects after the intervention, in the CRF group facial numbness and weakness of muscle of mastication were reported. Whereas, there were no side effects reported in the PRF group. This data augments study by Zhao et al., who described few or minimal side effects profile for the PRF group. ${ }^{23}$

Facial numbness was observed in 15 patients (100\%) in the TRF group. There was a statistically significant difference in the incidence of facial numbness between groups receiving $\mathrm{CRF}$ and PRF $(\mathrm{p}<0.001)$. Complications such as facial numbness resolved in a short time. None of the study patients developed any other complications or had permanent complications. The incidence of facial numbness in these study group CRF was like that reported in previous studies $(50.8 \%-100 \%) .{ }^{16,25}$ It is postulated that the increase in the temperature is associated with the increase in risk of complications. ${ }^{23,24}$ 
CRF patients had better VAS scores at the 6-month time compared to the PRF group. This result collaborates with recently published research about the therapeutic efficacy of PRF treatment. Although it is widely acknowledged that the efficacy of CRF is superior to PRF, the nondestructive nature of PRF is still promising. ${ }^{26-28}$

In our study, we used fMRI to compare the affected versus the non-affected side of the brain before and after radiofrequency ablation of the Gasserien ganglion. Niemeier found similar changes in the lingual gyrus, postcentral gyrus, paracentral lobule, inferior cerebellum, and inferior cerebellum of patients with suffering from $\mathrm{TN} .^{29}$

Author Yuan found that patients with primary TN had substantially altered Reho and fractional ALFF values in the cerebellum's right posterior lobe, suggesting functional changes. ${ }^{30}$

Reduced BOLD signal activation was observed in some brain regions after radiofrequency ablation compared to that before the radiofrequency. The activation was markedly reduced in the secondary somatosensory area and the frontal operculu. Villain cited in 2011 that the central nervous system functional improvements in $\mathrm{TN}$ patients after the radiofrequency procedure, including postcentral gyrus (S1), insula, anterior cingulate cortex, inferior parietal lobule, middle temporal gyrus, fusiform gyrus, and calcarine, are related to sensory, affective, and emotional processes. ${ }^{31}$

\section{Conclusion}

From our study it can be concluded that both thermal and pulsed radiofrequency are effective and safe in the treatment of patients with TN. Thermal radiofrequency appears to have adequate pain relief up to 6 months, but with some transient side effects that may be unpleasant for the patient. fMRI show reduced in brain activity in some brain regions after 1 month of radiofrequency but this was a not significant finding.

\section{Conflict of interests}

None declared by the authors. All funding on the study provided by the institution.

\section{Authors' contribution}

SK, RS: conduction of the study, manuscript editing,

AH, AM, MS: Concept, conduct of the study work and manuscript editing.

\section{References}

1. Abd-Elsayed A, Kreuger L, Seeger S, Dulli D. Pulsed Radiofrequency for Treating Trigeminal Neuralgia. Ochsner J. 2018 Spring;18(1):63-65. [PubMed] [Free Full Text]

2. van Hecke O, Austin SK, Khan RA, Smith BH, Torrance N. Neuropathic pain in the general population: a systematic review of epidemiological studies. Pain. 2014 Apr:155(4):654-62. [PubMed] DOI: 10.1016/i.pain.2013.11.013

3. Duransoy $Y K$, Mete $M$, Akçay E, Selçuki M. Differences in individual susceptibility affect the development of trigeminal neuralgia. Neural Regen Res. 2013 May 15;8(14):1337-42. [PubMed] [Free Full Text] DOI: $10.3969 / j$ issn.1673-5374.2013.14.010

4. Sekula RF Jr, Frederickson AM, Jannetta PJ, Quigley MR, Aziz KM, Arnone GD. Microvascular decompression for elderly patients with trigeminal neuralgia: a prospective study and systematic review with meta-analysis. J Neurosurg. 2011 Jan;114(1):172-9. [PubMed] DOI: 10.3171/2010.6.JNS10142

5. Foley PL, Vesterinen HM, Laird BJ, Sena ES, Colvin LA, Chandran $S$, et al. Prevalence and natural history of pain in adults with multiple sclerosis: systematic review and meta-analysis. Pain. 2013 May;154(5):632-42. [PubMed] DOI: 10.1016/j.pain.2012.12.002

6. Cruccu, G., Biasiotta, A., Galeotti, F., lannetti, G., Innocenti, P., Romaniello, A. \& Truini, A. 2006. Diagnosis of trigeminal neuralgia: a new appraisal based on clinical and neurophysiological findings. Supplements to Clinical neurophysiology. Elsevier.

7. Headache Classification Committee of the International Headache Society (IHS). The International Classification of Headache Disorders, 3rd edition (beta version). Cephalalgia. $2013 \quad$ Jul;33(9):629-808. [PubMed] [Free Full Text] DOI: $10.1177 / 0333102413485658$

8. Eller JL, Raslan AM, Burchiel KJ. Trigeminal neuralgia: definition and classification. Neurosurg Focus. 2005 May 15;18(5):E3. [PubMed] DOl: 10.3171/foc.2005.18.5.4

9. Kitt CA, Gruber K, Davis M, Woolf CJ, Levine JD. Trigeminal neuralgia: 
opportunities for research and treatment. Pain. $2000 \quad$ Mar;85(1-2):3-7. [PubMed] DOI: 10.1016/s0304-3959(99)00310-3

10. Quesada G, Baptista CE, Daiana SP, Douglas LF. Trigeminal neuralgia - from diagnosis to treatment [in Spanish]. Revista Dentística. 2005; 11.

11. Oesman C, Mooij JJ. Long-term follow-up of microvascular decompression for trigeminal neuralgia. Skull Base. 2011 Sep;21(5):313-22. [PubMed] [Free Full Text] DOI: $10.1055 / \mathrm{s}-0031-1284213$

12. Lopez BC, Hamlyn PJ, Zakrzewska JM. Systematic review of ablative neurosurgical techniques for the treatment of trigeminal neuralgia. Neurosurgery. 2004 Apr;54(4):973-82; discussion 982-3. [PubMed] DOI: 10.1227/01.neu.0000114867.98896.f0

13. Van Zundert J, Brabant S, Van de Kelft E, Vercruyssen A, Van Buyten JP. Pulsed radiofrequency treatment of the Gasserian ganglion in patients with idiopathic trigeminal neuralgia. Pain. 2003 Aug;104(3):449-52. [PubMed] DOI: $10.1016 / \mathrm{s} 0304-3959(03) 00066-6$

14. Devor A, Dunn AK, Andermann ML, Ulbert I, Boas DA, Dale AM. Coupling of total hemoglobin concentration, oxygenation, and neural activity in rat somatosensory cortex. Neuron. 2003 Jul 17;39(2):353-9. [PubMed] [Free Full Text] DOI: 10.1016/s0896-6273(03)00403-3

15. Logothetis NK, Pauls J, Augath $M$, Trinath T, Oeltermann A. Neurophysiological investigation of the basis of the fMRI signal. Nature. 2001 Jul 12;412(6843):1507. [PubMed] DOI: $10.1038 / 35084005$

16. Yao $\mathrm{P}$, Hong $\mathrm{T}$, Zhu $\mathrm{YQ}$, Li HX, Wang ZB, Ding YY. Efficacy and safety of continuous radiofrequency thermocoagulation plus pulsed radiofrequency for treatment of $\mathrm{V} 1$ trigeminal neuralgia: A prospective cohort study. Medicine (Baltimore). 2016 Nov;95(44):e5247. [PubMed] [Free Full Text]

DOI: $10.1097 / M D .0000000000005247$

17. Elawamy A, Abdalla EEM, Shehata GA. Effects of Pulsed Versus Conventional Versus Combined Radiofrequency for the Treatment of Trigeminal Neuralgia: A Prospective Study. Pain Physician. 2017 Sep;20(6):E873-E881. [PubMed] [Free Full Text]

18. Erdine S, Ozyalcin NS, Cimen A, Celik M, Talu GK, Disci R. Comparison of pulsed radiofrequency with conventional radiofrequency in the treatment of idiopathic trigeminal neuralgia. Eur $\mathrm{J}$ Pain.
2007 Apr:11(3):309-13.

DOI: 10.1016/j.ejpain.2006.04.001

[PubMed]

19. Laghmari $M$, El Ouahabi A, Arkha $Y$, Derraz S, El Khamlichi A. Are the destructive neurosurgical techniques as effective as microvascular decompression in the management of trigeminal neuralgia? Surg Neurol. 2007 Nov:68(5):505-12. DOI: $10.1016 /$.j.surneu.2006.11.066

20. Fraioli MF, Cristino $B$, Moschettoni $L$, Cacciotti G, Fraioli C. Validity of percutaneous controlled radiofrequency thermocoagulation in the treatment of isolated third division trigeminal neuralgia. Surg Neurol. 2009 Feb;71(2):180-3. [PubMed] DOI: 10.1016/j.surneu.2007.09.024

21. Kim JH, Yu HY, Park SY, Lee SC, Kim YC. Pulsed and conventional radiofrequency treatment: which is effective for dental procedure-related symptomatic trigeminal neuralgia? Pain Med. 2013 Mar;14(3):4305. [PubMed] DOI: $10.1111 / \mathrm{pme} .12046$

22. Wu H, Zhou J, Chen J, Gu Y, Shi L, Ni H. Therapeutic efficacy and safety of radiofrequency ablation for the treatment of trigeminal neuralgia: a systematic review and meta-analysis. J Pain Res. 2019 Jan 18;12:423-441. [PubMed] [Free Full Text] DOI: $10.2147 / J P R . S 176960$

23. Zhao $W X$, Wang $Q$, He MW, Yang $L Q$, Wu BS, $\quad \mathrm{Ni} \quad J X . \quad$ Radiofrequency thermocoagulation combined with pulsed radiofrequency helps relieve postoperative complications of trigeminal neuralgia. Genet Mol Res. 2015 Jul 13;14(3):761623. [PubMed] [Free Full Text] DOI: 10.4238/2015.July.13.5

24. Ding $\mathrm{Y}$, Li H, Hong $\mathrm{T}$, Zhu $\mathrm{Y}$, Yao $\mathrm{P}$, Zhou G. Combination of Pulsed Radiofrequency with Continuous Radiofrequency Thermocoagulation at Low Temperature Improves Efficacy and Safety in V2/N3 Primary Trigeminal Neuralgia. Pain Physician. $2018 \quad$ Sep;21(5):E545-E553. [PubMed] [Free Full Text]

25. Tang $Y Z$, Wu BS, Yang LQ, Yue JN, He $\mathrm{LL}$, $\mathrm{Li} \mathrm{N}$, et al. The Long-Term Effective Rate of Different Branches of Idiopathic Trigeminal Neuralgia After Single Radiofrequency Thermocoagulation: A Cohort Study. Medicine (Baltimore). 2015 Nov;94(45):e1994. [PubMed] [Free Full
Text] 10.1097/MD.0000000000001994

26. Luo F, Meng L, Wang $T, Y u$, Shen $Y$, Ji $N$. Pulsed radiofrequency treatment for idiopathic trigeminal neuralgia: a 
retrospective analysis of the causes for ineffective pain relief. Eur J Pain. 2013 Sep;17(8):1189-92. [PubMed] DOI: 10.1002/j.1532-2149.2012.00278.x

27. Wu H, Zhou J, Chen J, Gu Y, Shi L, Ni H. Therapeutic efficacy and safety of radiofrequency ablation for the treatment of trigeminal neuralgia: a systematic review and meta-analysis. J Pain Res. 2019 Jan 18:12:423-441. [PubMed] [Free Full Text] DOI: $10.2147 / J P R . S 176960$

28. Zeng $F$, Zhu $M$, Wan $Q$, Yan $Y$, Li C, Zhang $Y$. The treatment of $V 2+V 3$ idiopathic trigeminal neuralgia using peripheral nerve radiofrequency thermocoagulation via the foramen rotundum and foramen ovale compared with semilunar ganglion radiofrequency thermocoagulation. Clin Neurol Neurosurg. 2020 Sep;196:106025. [PubMed] DOI: $\underline{10.1016 / j . c l i n e u r o .2020 .106025}$
29. Rodriguez-Raecke $R$, Niemeier $A$, lhle $K$, Ruether W, May A. Brain gray matter decrease in chronic pain is the consequence and not the cause of pain. $J$ Neurosci. 2009 Nov 4;29(44):13746-50. [PubMed] [Free Full Text] DOI: 10.1523/JNEUROSCI.3687-09.2009

30. Yuan J, Cao S, Huang $Y$, Zhang $Y$, Xie P, Zhang $Y$, et al. Altered Spontaneous Brain Activity in Patients With Idiopathic Trigeminal Neuralgia: A Resting-state Functional MRI Study. Clin J Pain. 2018 Jul;34(7):600-609. [PubMed] [Free Full Text]

DOI: 10.1097/AJP.0000000000000578

31. Moisset $X$, Villain $N$, Ducreux $D$, Serrie $A$, Cunin G, Valade D. Functional brain imaging of trigeminal neuralgia. Eur $\mathrm{J}$ Pain. 2011 Feb;15(2):124-31. [PubMed] DOI: $10.1016 /$ j.ejpain.2010.06.006 